\title{
Late onset of isovaleric acidemia presenting with bicytopenia
}

\author{
Bisitopeni ile birliktelik gösteren geç başlangıçl izovalerik asidemi
}

\author{
Barış Malbora ${ }^{1}, Z_{\text {Zekai Avcı }}^{1}$, Alev Hasanoğlu ${ }^{2}$, Füsun Alehan³ ${ }^{3}$ Namık Özbek ${ }^{1}$ \\ ${ }^{1}$ Department of Pediatric Hematology, Başkent University Faculty of Medicine, Ankara, Turkey \\ ${ }^{2}$ Department of Pediatric Metabolism, Gazi University Faculty of Medicine, Ankara, Turkey \\ ${ }^{3}$ Department of Pediatric Neurology, Başkent University Faculty of Medicine, Ankara, Turkey
}

\section{To the Editor,}

Isovaleric academia (IVA) is an autosomal recessive inborn error of leucine metabolism caused by a deficiency of isovaleryl-CoA dehydrogenase. In the acute phase of this disease, thrombocytopenia, neutropenia or pancytopenia may be common features [1-4]. However, the physiopathology of the bone marrow suppression in this disease is still unclear. Here, we report the case of an IVA patient who presented with thrombocytopenia and neutropenia at the age of 31 months.

A 31-month-old male patient had been admitted to our hospital with fever, vomiting, fatigue, and loss of appetite. There was no history of any drug use. On physical examination, the patient was lethargic. Vital signs were normal except for mild tachycardia and tachypnea. Skin turgor and tonus were found to be decreased.

The results of a complete blood count revealed the following: white blood cells (WBC) count $1.4 \times 10^{9} / \mathrm{L}$; absolute neutrophil count $0.92 \times 10^{9} / \mathrm{L}$; hemoglobin $11 \mathrm{~g} / \mathrm{dl}$; and platelet count $57.5 \times 10^{9} / \mathrm{L}$. The bone marrow aspiration showed normal maturation of three lineages without any hemophagocy- tosis, megaloblastic cells, extramyeloid cells, fatty changes, or myelodysplasia. There were numerous necrotic cells. The number and the morphology of megakaryocytes were normal. In the aspiration smear, $18 \%$ myelocyte, 35\% metamyelocyte, $11 \%$ polymorphonuclear leukocyte, $28 \%$ lymphocyte, $2 \%$ normoblast, $1 \%$ monocyte, $1 \%$ eosinophil, and $4 \%$ lymphoblast-like cells were present. Bone marrow flow cytometry did not reveal lymphoblasts. Biochemical analyses were within normal limits except for hypocalcemia, hyperammonemia, and mildly increased aspartate aminotransferase and lactate dehydrogenase. Serum C-reactive protein and erythrocyte sedimentation rate were in normal range. Ketonuria was determined. The results of blood, throat, urine, stool, and cerebrospinal fluid cultures were negative. Viral serology of the cerebrospinal fluid and serum were also negative. Serum Brucella agglutination and Salmonella agglutination were negative. Serum lactate and pyruvate levels were $4 \mathrm{mmol} / \mathrm{L}$ (normal range: 0.7-2.1 $\mathrm{mmol} / \mathrm{L}$ ), and $2.74 \mathrm{mg} / \mathrm{dl}$ (normal range: $0.3-1 \mathrm{mg} /$ $\mathrm{dl})$, respectively. The urine organic acid examination showed that the excretions of isovaleryl glycine and methyl malonic acid were significantly 


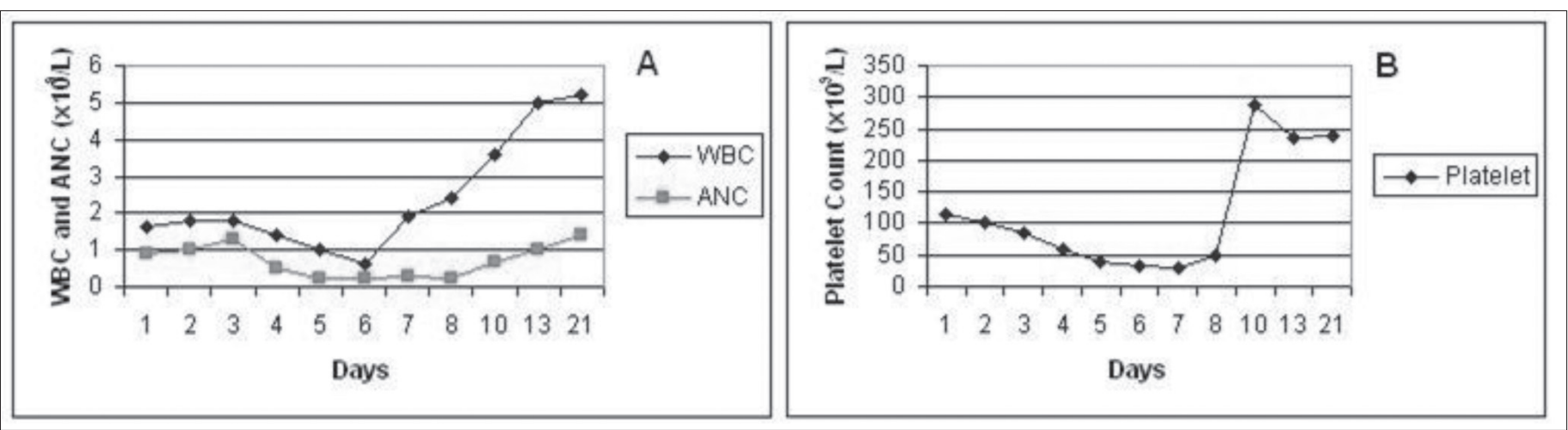

Figure 1. The hematologic parameters of the patient during isovaleric acidemia episode. A) WBC (white blood cell) and ANC (absolute neutrophil count), B) Platelet count

increased: $1299 \mathrm{mmol} / \mathrm{mol}$ creatinine (normal: 0 $\mathrm{mmol} / \mathrm{mol}$ creatinine) and $42.7 \mathrm{mmol} / \mathrm{mol}$ creatinine (normal: $0 \mathrm{mmol} / \mathrm{mol}$ creatinine), respectively. Tandem mass spectrometry of spot serum, free carnitine and amino acid profiles were normal. There was an increase in the isovaleryl and 3-OH butyryl carnitine levels, whereas there was a decrease in the levels of acetyl, propionyl, and palmitoylcarnitine. Lymphocyte isovaleryl-CoA dehydrogenase activity was $0.02 \mathrm{nmol} / \mathrm{min} . \mathrm{mg}$ [controls mean $\pm \mathrm{SD}$ : $1.51 \pm 0.31 \mathrm{nmol} / \mathrm{min} . \mathrm{mg}]$.

We initiated antibiotic therapy and protein-poor diet. Carnitine and L-glycine were added to the treatment. During this period, his laboratory examination revealed WBC count of $0.64 \times 10^{9} / \mathrm{L}$ (absolute neutrophil count, $0.43 \times 109 / \mathrm{L}$ ); a hemoglobin level of $10.7 \mathrm{~g} /$ $\mathrm{dl}$; and a platelet count of $31.8 \times 10^{9} / \mathrm{L}$. On the fifth day of antibiotics, his fever was controlled, and the WBC number and platelet count began to increase. His blood count was completely normal one week after the end of antibiotic treatment (Figure 1a, b).

Hematologic problems can be seen in patients with inborn errors of branched-chain amino acid metabolism. Various cytopenias have been reported in IVA [5]. However, the physiopathology of myelosuppression in this disease is not well known. Some infections may also result in myelosuppression, but in our patient, we did not determine any serologic or microbiologic evidence of infection. There is also a report of a patient with IVA with promyelocytic myeloproliferative syndrome [6,7]. In patients with IVA, hematologic problems are usually reported in early infancy $[1,2,6]$. Compatible with this, no patients have been reported in the English literature with IVA diagnosed later in childhood with neutropenia, thrombocytopenia or pancytopenia.
In some patients, this disorder may be diagnosed as late as 5 years [8]. However, hematologic problems are not observed at that age. Another interesting finding in our patient was the lymphoblast-like cells observed in the bone marrow. We believe that the lymphoblast-like cells observed in our patient's bone marrow were due to maturation arrest in the normal lymphoblastic series caused by IVA.

Although both forms of IVA often occur in the first year of life, IVA may be observed later in childhood. Hematologic problems frequently observed in the acute form of the disease can be seen in the chronic intermittent form, as was the case in our patient. Thus, in such cytopenias, inborn errors of branched -chain amino acid metabolism, like IVA, should be kept in mind.

\section{Acknowledgement}

This study conforms to the principles outlined in the Declaration of Helsinki (1975) and later revisions, and was approved by Ethical Committee of Baskent University Faculty of Medicine, Ankara, Turkey.

\section{Conflict of Interest}

No author of this paper has a conflict of interest, including specific financial interests, relationships, and/or affiliations relevant to the subject matter or materials included in this manuscript.

\section{References}

1. Newman CG, Wilson BD, Callaghan P, Young L. Neonatal death associated with isovaleric acidaemia. Lancet 1967;2:439-42.

2. Fischer AQ, Challa VR, Burton BK, McLean WT. Cerebellar hemorrhage complicating isovaleric acidemia: a case report. Neurology 1981;31:746-8.

3. Hou JW, Wang TR. Isovaleric acidemia: report of one case. Zhonghua Min Guo Xiao Er Ke Yi Xue Hui Za Zhi 1990;31:262-5. 
4. Kelleher JF Jr, Yudkoff M, Hutchinson R, August CS, Cohn RM. The pancytopenia of isovaleric acidemia. Pediatrics 1980;65:1023-7.

5. Guerra-Moreno J, Barrios N, Santiago-Borrero PJ. Severe neutropenia in an infant with methylmalonic acidemia. Bol Asoc Med P R 2003;95:17-20.

6. Gilbert-Barness E, Barness LA. Isovaleric acidemia with promyelocytic myeloproliferative syndrome. Pediatr Dev Pathol 1999;2:286-91.
7. Hutchinson RJ, Bunnell K, Thoene JG. Suppression of granulopoietic progenitor cell proliferation by metabolites of the branched-chain amino acids. J Pediatr 1985;106:62-5.

8. Berry GT. Inborn errors of carbohydrate, ammonia, amino acid, and organic acid metabolism. In: Ballard RA, Berry GT, editors. Avery's Diseases of the Newborn. 8th ed. Philadelphia: Elsevier Saunders, 2005:227-57. 